\title{
ALÉM DAS LETRAS: PROPOSTA DE INTEGRALIZAÇÃO ENTRE CORPO DOCENTE, BIBLIOTECA ESCOLAR E COORDENAÇÃO PEDAGÓGICA
}

\author{
Jussara Ventura dos Santos \\ Mestre em Ciência da Informação \\ ventura.jussara@gmail.com
}

\section{INTRODUÇÃO}

O crescimento do fluxo informacional é o propulsor das mudanças vistas nos últimos anos na sociedade da informação. A multiplicidade de valores que permeia todo o contexto cultural pode ser atribuída ao grande volume de informações que chegam aos usuários sem nenhum tipo de tratamento ou filtragem e vem desencadeando uma verdadeira revolução no que diz respeito à construção do conhecimento, visto que em uma sociedade onde a informação é cada vez mais valorizada, quem a detém leva vantagem sobre seus oponentes na hora de tomada de decisões, tanto no campo profissional quanto em sua vida social, pessoal e emocional.

Nesse cenário é possível identificar, em meio a luta pela sobrevivência, uma intensificação do que antes era considerado apenas uma máxima ainda em processo de aceitação: a de que informação é poder. $O$ surgimento acelerado de novas tecnologias de informação e comunicação - TICs, com a finalidade de proporcionar a seus usuários a tão ansiada melhora na qualidade de vida, é bem vindo e, até mesmo, necessário. No entanto, como efeito colateral, também é observado uma escassez de tempo quando direcionado ao trato de questões consideradas corriqueiras do ser social.

Com isso, valores e tradições transmitidos por meio da oralidade em meio ao seio familiar passam por um período de crise, e os responsáveis por essa transmissão de conhecimento delegam, ou inferem estar delegando, essa missão para o Estado, por meio da educação formal. Em contrapartida, sentindo esse desvio de função para seu lado da balança, o Estado refuta essa atribuição e explicita seu posicionamento quanto ao caso quando reforça que a educação das crianças é tarefa da família e que às escolas é cabível o papel de ensinar apenas as disciplinas formais.

Em meio a essa problemática que envolve educação formal, informal e até mesmo social, a pergunta que nos fazemos enquanto profissionais da informação e suas multifacetas é: o que pode ser feito para amenizar os efeitos da metanóia instaurada em meio a sociedade?

Do ponto de vista social esse estudo busca promover, por meio de eventos pedagógicos, o resgate de práticas que vêm sendo visivelmente negligenciadas e, possivelmente, responsáveis pela violência que assola os dias atuais. A ausência de transmissão de preceitos pode ser geradora da supressão de respeito à vida, ao ser humano, ao planeta, ou seja, às regras básicas da convivência repassadas de pai para filho por muitos e muitos anos.

Destarte, fomentar estudos com essa temática se faz urgente para que possamos sanar problemas produzidos em meio às vicissitudes aqui expostas. O nascimento de uma filha temporã e, consequentemente, o retorno às questões educacionais de base constituem a motivação pessoal para esse tipo de investigação.

Esta pesquisa tem como objetivo geral: contribuir para o debate sobre as formas de planejar, projetar, desenvolver, implementar ações que promovam a integralização entre os três pilares da educação: ensino, pesquisa e extensão, aqui representados respectivamente pelo corpo docente, biblioteca escolar e coordenação pedagógica.

A partir do objetivo geral, esta pesquisa tem por objetivos específicos:

- Realizar o levantamento bibliográfico em livros, documentos oficiais, artigos, teses e dissertações sobre as possibilidades de articulação entre $\mathrm{o}$ 
caráter teórico e a aplicação prática do desenvolvimento de ações que impulsionem esse modelo de aprendizagem.

- Identificar teorias de como se processa a aprendizagem ("como se aprende"), e seus fundamentos para a estruturação de conteúdos ("como ensinar") apoiados por objetos de aprendizagem;

- Analisar a utilização de recursos tradicionais e/ou digitais de aprendizagem na prática pedagógica.

\section{METODOLOGIA DA PESQUISA}

Esta pesquisa foi conduzida de acordo com a abordagem exploratória e descritiva, de natureza qualitativa, na qual pretendemos estimular a investigação e análise sobre os desafios do desenvolvimento de eventos integrados que possibilitem o uso de objetos de aprendizagem inserindo-os no calendário escolar.

A motivação em adotarmos o método qualitativo é devido ao fato de concordarmos com Alves-Mazzotti e Gewandsznajder (1998), quando afirmam que na pesquisa qualitativa, a principal preocupação é contextualizar o objeto de estudo em uma realidade social dinâmica, intertextualizando relações, interações e implicações advindas de uma situação específica, com o objetivo de uma análise mais profunda e significativa do objeto investigado.

$\mathrm{Na}$ perspectiva de Bogdan e Biklen (1994), na investigação qualitativa o pesquisador precisa se "preocupar com o contexto", ou seja, entender que "[...] as ações podem ser melhor compreendidas quando são observadas no seu ambiente natural de ocorrência". Os autores entendem que "[...] os locais têm de ser entendidos no contexto da história das instituições a que pertencem" e a pesquisa qualitativa busca um todo maior, no qual várias tipologias são consideradas: pesquisa etnográfica, estudo de campo, entrevista em profundidade e descritiva.

$\mathrm{Na}$ pesquisa qualitativa os participantes da investigação são considerados coautores do trabalho, elementos potenciais para a análise interpretativa, negociada e considerada sob diversos pontos de vista. Para Marconi (2005), a natureza desse tipo de pesquisa incorpora uma multiplicidade de visões, comentários e críticas e conduz a múltiplas interpretações e ações, cujas principais características são:

a) Orientação para o futuro, facilitando a criação de soluções voltadas para um ideal desejável pelos interessados;

b) Colaboração entre pesquisadores e participantes;

c) Desenvolvimento da capacidade de identificar e resolver problemas;

d) Geração de teoria fundamentada na ação confirmada ou revisada por meio da avaliação de sua adequação à ação.

Esta pesquisa busca a articulação entre teoria e prática no processo de construção do conhecimento, ou seja, a dimensão teórica é fonte onde se privilegia a reflexão, assim como a dimensão teórica e reflexiva se convertem em ação, em intervenção social e educacional, possibilitando aos pesquisadores uma atuação efetiva sobre a realidade a ser investigada.

A realidade a ser estudada favorece o acompanhamento e a avaliação de dimensões teóricas e práticas, verificando os fatores e as ações desenvolvidas pelo corpo social (educadores e alunos) e que determinam as características mais marcantes do desenvolvimento desses eventos e o uso de objetos de aprendizagem utilizados especificamente para esse fim.

Buscamos fazer um percurso para responder às principais questões da pesquisa a partir do entendimento de que a implantação/implementação dessa integralização de pilares na educação é resultado de um processo contínuo de avaliação. Esse processo de avaliação, por sua vez, foi elaborado com a finalidade não só de atestar a conformidade dos processos pedagógicos e gerenciais e dos resultados alcançados, como também identificar sucessos e insucessos da concepção, desenvolvimento dessas práticas nas escolas participantes da pesquisa.

Simultaneamente, para a organização desses eventos e escolha para utilização de objetos de aprendizagem que subsidiem as reflexões da pesquisa, as atividades foram 


\section{Anais do Encontro Paraibano de Biblioteca Escolar}

divididas em três diferentes etapas específicas: pré-campo, campo e pós-campo, descritas a seguir.

a) Etapa pré-campo

- Revisão bibliográfica sobre objetos de aprendizagem;

- Realização de estudos que permitirão detalhamento/refinamento das etapas e dos procedimentos metodológicos;

- Elaboração dos instrumentos de coleta de dados;

- Organização da estrutura geral para o desenvolvimento da pesquisa.

b) Etapa de campo

- Reuniões com as equipes que utilizarão os objetos de aprendizagem;

- Implementação da formação dos educadores para utilização de objetos de aprendizagem;

- Coleta de dados;

- Elaboração de relatórios intermediários

c) Etapa pós-campo

- Crítica dos dados;

- Análise dos dados;

- Elaboração do relatório de resultados.

Para a concepção dessa modelagem tivemos as seguintes atividades que ocorreram simultaneamente às três etapas destacadas anteriormente:

- Análise das necessidades, audiência, gestão pedagógica e tecnológica, mídias, custos, cronograma;

- Design da proposta pedagógica, recursos didáticos, conteúdos e estratégias para utilização de objetos de aprendizagem nos componentes de Língua Portuguesa, Práticas Sociais e Ciências;
- Implementação dos objetos de aprendizagem nas atividades pedagógicas;

- Avaliação do processo de inserção desses eventos integrados no calendário escolar.

\section{FUNDAMENTOS TEÓRICOS PARA A DIVERSIFICAÇÃO DE ATIVIDADES ESCOLARES}

A educação é um campo que está em constante movimento para acompanhar o processo evolutivo tão natural da sociedade. É notória a mudança de paradigmas no que diz respeito ao processo ensino/aprendizagem. $\mathrm{O}$ modelo tradicional adotado por anos, ou seja, a sala de aula com seu mobiliário convencional em sua maioria encerrada entre quatro paredes, não atende mais as necessidades da geração nativa digital. São métodos e técnicas obsoletos que dificultam a prática educacional condizente como os novos tempos, o modo de se pensar mudou. Estudos revelam que a geração atual tem uma forma própria de pensar e se expressar, sua rede neural recebe estímulos que traduzem uma mudança ímpar em seu poder cognitivo.

A proposta de pesquisa de integralização de pilares com vistas à união de saberes peculiares a cada um deles aduz a superação da convencional tradição expositivodescritiva visando levar tanto os alunos quanto os educadores a construírem juntos o conhecimento. A caracterização formativa e comprometida com o processo de ensino/aprendizagem de cada um desses pilares, ou seja, ao corpo docente, a biblioteca escolar e a coordenação pedagógica, atribui aos mesmos a função articuladora nessa construção.

\subsection{OBJETOS DE APRENDIZAGEM}

$\mathrm{Na}$ organização das atividades escolares, educadores investem um tempo precioso planejando e trabalhando na elaboração de recursos para dinamizar aulas, demonstrar teorias e desenvolver conteúdos. Segundo Longmire (2000), uma das formas que pode apoiar a organização do trabalho pedagógico é a utilização de objetos digitais de aprendizagem. 
$\mathrm{O}$ conceito de objetos digitais de aprendizagem é relativamente novo e, portanto, pessoas e instituições estão aprendendo as melhores práticas para sua produção, gerenciamento e atualização. Para Polsani (2002), os objetos digitais de aprendizagem têm como principal característica o fato de serem reutilizáveis em diferentes situações ou contextos.

Segundo Wiley (2002), um objeto de aprendizagem abrange qualquer recurso digital, seja ele de pequeno ou grande porte, que possa ser reutilizado para apoiar a aprendizagem. Exemplos de pequenos recursos digitais incluem imagens, fotografias, animações, vídeos, textos e publicações Web. São exemplos de grandes recursos digitais que incluem páginas Web combinados com textos, imagens e outras mídias, com o propósito de construir um evento de instrução completo.

Segundo Muzio (2001) o objeto de aprendizagem é "[...] um granular, reutilizável pedaço de informação independente de mídia". O mesmo autor define como "[...] objetos educacionais, objeto independente, componente de treinamento, pepita ou pedaço". Também destaca que "[...] estes objetos vão desde mapas e gráficos até demonstrações em vídeo e simulações interativas". Para o autor, os objetos de aprendizagem permitem a utilização de pequenos componentes, que podem ser reutilizados inúmeras vezes, em diferentes contextos de aprendizagem.

Uma perspectiva que não se pode perder de vista ao utilizar criticamente objetos de aprendizagem é a necessidade de buscar elementos para a ampliação de competências empíricas (capacidade de pesquisar informações), analíticas (capacidade de interpretar informações) e avaliativas (capacidade de pensar as consequências educativas do trabalho desenvolvido) de cada sujeito participante de um processo educacional, permitindo, assim, uma avaliação constante dos caminhos percorridos em cada situação.

\section{CONSIDERAÇÕES FINAIS: A ORGANIZAÇÃO E ATUAÇÃO DAS}

\section{ESCOLAS PARA PARTICIPAÇÃO NA PESQUISA}

Para a organização e participação das escolas na pesquisa tomamos como diretriz que o uso adequado de qualquer recurso tecnológico na educação depende de estratégias, metodologias, reflexões e práticas relativas ao processo de aprendizagem dos alunos e as situações didáticas necessárias para que estes construam novos conhecimentos.

Assim, a comunidade escolar foi estimulada a se organizar para desenvolver uma postura que comporta ações centradas na aprendizagem dos alunos, como as que seguem:

- Propor atividades a serem desenvolvidas com materiais diversificados, tendo em vista a resolução de problemas;

- Criar situações em que os alunos sejam desafiados e estimulem a reflexão e a descoberta;

- Investir esforços na construção de relações que valorizem uma efetiva interação do educador com os alunos e dos alunos uns com os outros, estimulando a interação em atividades de grupo que envolvam cooperação e troca de ideias. Assim, a situação "social" de escola como um todo, não poderá ser autoritária, repressiva, esvaziada de uma relação humana e de vida.

- Oferecer alternativas para retomar o percurso de construção dos conhecimentos nos quais os alunos tiverem dificuldades, atendendo prioritariamente os objetivos de:

- Oferecer novos caminhos (metodologias e estratégias inovadoras) para apoiar a aprendizagem de Língua Portuguesa, Práticas Sociais e Ciências;

- Criar condições favoráveis à aquisição de habilidades e competências gerais, 
integradoras de todos os componentes curriculares;

- Aprofundar e ampliar conhecimentos adquiridos.

Estas propostas foram desenvolvidas com atividades sugeridas a partir das seguintes práticas:

- $\quad$ Promover atividades criativas de produção de saberes por meio de encontros, jornadas, feiras, etc.

\section{REFERÊNCIAS}

ALVES-MAZZOTTI, Ana Judith; GEWANDSZNAJDER, Fernando. O Método das Ciências Naturais. 2. ed. São Paulo: Pioneira, 1998.

BOGDAN, Roberto C.; BIKLEN, SariKnopp. Investigação qualitativa em educação: uma introdução à teoria e aos métodos. Porto: Porto Editora, 1994.

LONGMIRE, W. (2000). A Primer On Learning Objects. Disponível em: < http://archive2.nmc.org/projects/lo/sap_ltt_lo ngmire.shtml > Acesso em 16/08/2016.

MARCONI, Marina de Andrade; LAKATOS, Eva Maria. Fundamentos de metodologia científica. 6 Ed. São Paulo: Atlas, 2005.

MUZIO, J.; HEINS, T.; MUNDELL, R. (2001) Experiences with Reusable eLearning Objects: From Theory to Practice. Disponível em:

<http://www.udutu.com/pdfs/eLearningobjects.pdf> Acesso em: 18/08/2016.

POLSANI, Pithamber R. The Use and Reusable Learning Objects. The University of Arizona, (2002). Disponível em :< http://journals.tdl.org/jodi/article/viewArticle/ 89/88>. Acesso em: 16/08/2016.

WILEY, David. Learning Objects Need Instructional Design Theory. In: ROSSETT, Allison. The Astd E-Learning Handbook: Best Practices, Strategies and Cases Studies for an emerging field. New York: McGrawHill, 2002. 